\title{
Icterícia de íris após rabdomiólise por esforço em um equino
}

\author{
Icterus iris after exertional rhabdomyolysis syndrome in a horse
}

\author{
Ubiratan Pereira de Melo $^{I^{*}}$ Cíntia Ferreira ${ }^{\mathrm{I}}$ \\ Priscila Fantini ${ }^{\mathrm{I}}$ Kárita Dannielle Assis Borges ${ }^{\mathrm{I}}$
}

\section{- NOTA -}

\section{RESUMO}

Neste trabalho, é descrito um caso de icterícia de íris em equino da raça Paint. Ao exame clínico, foram observados tremores, dor muscular, relutância em andar, taquicardia, taquipnéia e icterícia de íris. As concentrações séricas de creatina cinase, aspartato aminotransferase, lactato desidrogenase e bilirrubina indireta estavam marcadamente elevadas. Com base na anamnese, sintomatologia clínica e bioquimica sérica, diagnosticou-se síndrome da rabdomiólise por esforço. Foram instituídos os seguintes tratamentos: terapia analgésica, fluidoterapia e restrição de exercício. Após seis dias, houve a remissão dos sinais clínicos e o retorno da coloração original da íris.

Palavras-chave: equino, síndrome da rabdomiólise por esforço, íris, icterícia.

\section{ABSTRACT}

One case of icterus iris diagnosed in an American Paint Horse is described. Stiffness, painful muscle, reluctance to move, elevated respiratory and heart rates, and icterus iris were observed in the clinical examination. Creatine kinase, aspartate aminotransferase, lactate dehydrogenase, alkaline phosphatase, and bilirubin levels were markedly elevated. Exertional rhabdomyolysis syndrome was diagnosed. Analgesic therapy, fluid therapy, and limited exercise were prescribed. After six days there was a remission of clinical signs and return the original color of the iris.

Key words: horse, exertional rhabdomyolysis syndrome, iris, icterus.
Durante anos, as miopatias equinas relacionadas ao exercício receberam várias denominações na literatura, incluindo azotúria, mioglobinúria paralítica, rabdomiólise intermitente crônica, rabdomiólise de esforço, síndrome do atamento ou miosite. Embora os termos englobem várias doenças associadas ao exercício, aparentemente, representam diferentes graus da mesma afecção. Do ponto de vista fisiopatológico, o termo síndrome da rabdomiólise por esforço (SRE) é o mais apropriado (BAXTER et al., 2006).

Casos esporádicos de SRE podem ocorrer após esforço extremo, excesso de exercício em relação ao grau de condicionamento e desequilíbrio hídricoeletrolítico ou nutricional. Outros equinos, no entanto, apresentam repetidos episódios de SRE com pouco exercício. Vários fatores têm sido descritos como predisponentes para a SRE, incluindo grupamento muscular significativo, exercício irregular, dieta rica em concentrado, idade e sexo. Outros fatores, tais como desequilíbrio eletrolítico, deficiência de vit. E/selênio, infecção viral, distúrbios hormonais e regulação intracelular anormal de cálcio têm sido descritos como predisponentes (VALENTINE et al., 1998).

Clinicamente, os equinos desenvolvem um andar rígido, particularmente, nos membros pélvicos. Taquicardia, taquipnéia, ansiedade, além de sudorese

IPrograma de Pós-graduação em Ciência Animal, Escola de Veterinária, Universidade Federal de Minas Gerais (UFMG), 31270-901, Belo Horizonte, MG, Brasil. E-mail: ubiratan_melo@yahoo.com.br. *Autor para correspondência. 
excessiva, são identificados. Alguns equinos são incapazes de caminhar devido à dor e contratura muscular, particularmente nos músculos glúteo, bíceps femoral, semitendinoso, semimembranáceo e epaxial. Nas formas mais graves, os equinos demonstram sinais de cólica, mioglobinúria e sensibilidade dolorosa à palpação muscular. A gravidade da condição nem sempre se relaciona à intensidade do exercício (HARRIS \& MAYHEW, 2000). O diagnóstico da SRE é baseado nos sinais clínicos e na elevação da concentração sérica da creatina cinase (CK), do lactato desidrogenase (LDH) e da aspartato transaminase (AST) (TEIXEIRA-NETO et al., 2008).

Os objetivos terapêuticos da SRE são controle da dor, restabelecimento do equilíbrio hídricoeletrolítico e prevenção de dano muscular adicional. O protocolo terapêutico varia em função da gravidade do episódio. Nos casos agudos, o exercício deve ser interrompido imediatamente, e medidas de suporte devem ser adotadas para tornar o equino tão confortável quanto possível até a instituição das medidas terapêuticas adequadas. Naqueles animais que apresentam tremores e dor muscular generalizada, a administração de fármacos anti-inflamatórios não esteroidais é benéfica. No entanto, se desidratação for evidente, a reidratação deve ser realizada antes da administração de qualquer fármaco (BAXTER et al., 2006).

Este artigo descreve um caso de SRE e icterícia de íris em um equino. Um garanhão da raça Paint, com 10 anos de idade e peso estimado de $400 \mathrm{~kg}$, foi submetido a uma cavalgada de $50 \mathrm{~km}$ após 40 dias de inatividade. Nove horas após o término da cavalgada, o proprietário observou que o equino apresentava andar rígido, relutância em se locomover e alteração da coloração dos olhos. Na manhã seguinte, o proprietário entrou em contato com o médico veterinário. $\mathrm{O}$ exame clínico revelou apatia, taquicardia (70bpm), taquipnéia (35mpm), tempo de perfusão capilar elevado ( $>2 \operatorname{seg}$ ) e elevação da temperatura corporal $\left(39,2^{\circ} \mathrm{C}\right)$. As mucosas oral e escleral encontravam-se ictéricas. O exame clínico do sistema musculoesquelético identificou aumento de volume e sensibilidade dolorosa nos músculos tríceps, epaxial, glúteo, bíceps femoral, semitendinoso e semimembranáceo. Exames laboratoriais, incluindo hematologia e bioquímica sérica, foram determinados e repetidos no segundo e no sexto dia de avaliação clínica, conforme demonstrado (Tabela 1).

Tabela 1 - Concentrações séricas de elementos bioquímicos no primeiro, no segundo e no sexto dia após episódio de síndrome da rabdomiólise equina por esforço.

\begin{tabular}{|c|c|c|c|c|}
\hline & $1^{\circ} \mathrm{dia}$ & $2^{\underline{o}}$ dia & $6^{o} \mathrm{dia}$ & Valores de referência ${ }^{* *}$ \\
\hline Proteína total & 7,5 & 7,0 & 6,5 & $6,5-7,5 \mathrm{mg} \mathrm{dl}^{-1}$ \\
\hline Albumina (A) & 3,9 & 3,4 & 3,1 & $2.6-3,7-\mathrm{mg} \mathrm{dl}^{-1}$ \\
\hline Globulina $(G)$ & 3,7 & 3,6 & 3,4 & $2.6-4,0 \mathrm{mg} \mathrm{dl}^{-1}$ \\
\hline Creatina fosfoquinase & 3.500 & 900 & 175 & $86-140 \mathrm{UI}^{-1}$ \\
\hline Lactato desidrogenase & 1.615 & 898 & 563 & $162-412 \mathrm{UI}^{1}{ }^{-1}$ \\
\hline Aspartato aminotransferase & 987 & 697 & 294 & $226-366 \mathrm{UI}^{-1}$ \\
\hline Fosfatase alcalina & 1.365 & 959 & 1.295 & $143-395 \mathrm{UI} \mathrm{I}^{-1}$ \\
\hline Alanina aminotransferase & 58 & 34 & 35 & $34-113 \mathrm{UI} \mathrm{I}^{-1}$ \\
\hline$\gamma$-glutamil transferase & 33 & 14 & 16 & $4-13,4 \mathrm{UI}^{-1}$ \\
\hline \multicolumn{5}{|l|}{ Bilirrubina } \\
\hline Conjugada (direta) & 0,50 & 0,50 & 0,30 & $0-0,4 \mathrm{mg} \mathrm{dl}^{-1}$ \\
\hline Não conjugada (indireta) & 3,9 & 3,79 & 2,10 & $0.2-2,0 \mathrm{mg} \mathrm{dl}^{-1}$ \\
\hline Total & 4,47 & 4,29 & 2,40 & $0-2,0 \mathrm{mg} \mathrm{dl}^{-1}$ \\
\hline Uréia & 77 & 70 & 41 & $10-24 \mathrm{mg} \mathrm{dl}^{-1}$ \\
\hline Creatinina & 3 & 2,1 & 1,5 & $1,2-1,9 \mathrm{mg} \mathrm{dl}^{-1}$ \\
\hline Ácido úrico & 1,2 & 0,7 & 0,6 & $0-1,0 \mathrm{mg} \mathrm{dl}^{-1}$ \\
\hline Sódio $\left(\mathrm{Na}^{+}\right)$ & 133 & 133 & 135 & $134-145 \mathrm{mEq} \mathrm{1}^{-1}$ \\
\hline Cloretos $\left(\mathrm{Cl}^{-}\right)$ & 85 & 88 & 103 & $99-105 \mathrm{mEq} \mathrm{1}^{-1}$ \\
\hline Potássio $\left(\mathrm{K}^{+}\right)$ & 5,4 & 5,0 & 5,0 & $3-5 \mathrm{mEq}^{-1}$ \\
\hline Magnésio $\left(\mathrm{Mg}^{2+}\right)$ & 2,7 & 2,5 & 2,1 & $1,4-2,5 \mathrm{mEq}^{-1}$ \\
\hline Cálcio total (tCa) & 9,1 & 9,6 & 11,2 & $11,2-13,6 \mathrm{mg} \mathrm{dl}^{-1}$ \\
\hline Cálcio ionizável (iCa) & 1,3 & 1,4 & 1,5 & $1,5-1,8 \mathrm{mmol} \mathrm{l}^{-1}$ \\
\hline
\end{tabular}

**Adaptado de FELDMAN et al. (2000).

Ciência Rural, v.39, n.7, out, 2009. 
O exame oftalmológico demonstrou intensa icterícia da íris em ambos os olhos e ausência de opacidade e edema corneal (Figura 1A). Os reflexos pupilares (direto e consensual) e dos nervos craniais (corneal, ameaça, palpebral), além do teste de acuidade visual estavam normais. O diagnóstico diferencial incluiu sobrecarga de carboidratos, deficiência de vit. E/selênio, laminite, tétano, babesiose e SRE. Com base no histórico, sinais clínicos e exames laboratoriais diagnosticou-se SRE. O tratamento consistiu de fluidoterapia intravenosa com solução salina fisiológica $0,9 \%\left(30 \mathrm{ml} \mathrm{kg}^{-1} \mathrm{dia}^{-1}\right)$ e ringer com lactato $\left(20 \mathrm{ml} \mathrm{kg}^{-1} \mathrm{dia}^{-1}\right)$ durante três dias, fenilbutazona ${ }^{\mathrm{a}}\left(4,4 \mathrm{mg} \mathrm{kg}^{-1} \mathrm{dia}^{-1} \mathrm{IV}\right)$ durante cinco dias e tiocolchicosídio $(12 \mathrm{mg}$ IM) a cada oito horas, durante quatro dias. $\mathrm{O}$ proprietário foi instruído a limitar o exercício até o retorno da função muscular normal, determinado pelos exames clínicos e laboratoriais. Dieta rica em gordura e pobre em carboidrato solúvel foi prescrita.

No segundo dia, o garanhão estava mais alerta, ingerindo água e alimentos, porém ainda apresentava andar rígido e relutância em se locomover. O exame clínico revelou taquicardia (60bpm), taquipnéia (30mpm) e temperatura corporal normal $\left(37,6^{\circ} \mathrm{C}\right)$. As membranas mucosas estavam ligeiramente ictéricas, $\mathrm{e}$ a íris estava marcadamente ictérica. Os parâmetros clínicos retornaram à normalidade no quinto dia; porém, o garanhão demonstrou sinais de leve desconforto abdominal. Ao exame clínico, todos os parâmetros vitais se encontravam dentro da faixa de normalidade. A auscultação abdominal revelou hipomotilidade intestinal em ambos antímeros. Na palpação transretal, diagnosticou-se compactação cecal. O tratamento consistiu de fluidoterapia enteral (cinco litros de água via sonda nasogástrica a cada hora) até resolução da compactação. Analgesia visceral não foi necessária. No sexto dia, o equino caminhava normalmente, e a coloração da íris (Figura 1B) e das mucosas havia retornado à coloração normal.

Aparentemente, dieta rica em concentrado e inatividade física atuaram como fatores predisponentes neste relato. Excesso de concentrados na dieta resulta no acúmulo de glicogênio na musculatura. Com o exercício, a quebra do glicogênio resulta na produção excessiva de lactato e no acúmulo deste no músculo, com consequente acidose intracelular, que pode prejudicar a glicólise e a homeostase ADP/ATP no sítio de ligação miosinaactina, resultando em aumento de ADP local e fadiga muscular (GOMIDE et al., 2006). Embora se acredite que os sinais clínicos de SRE resultem do acúmulo de lactato durante exercício, muitos equinos afetados não apresentam acúmulo de lactato e desenvolvem a doença durante exercício submáximo (MACLEAY et al., 2000). Atualmente acredita-se que a SRE seja resultante de alterações na regulação intracelular de cálcio e não da acidose láctica (ALEMAN, 2008). Além disso, se sabe que a produção excessiva de lactato pode inibir significativamente a ativação dos canais de $\mathrm{Ca}^{2+}$. Dessa forma, o processo de acoplamento contração-excitação e inibição da liberação de $\mathrm{Ca}^{2+}$, no retículo sarcoplasmático, pode contribui para a manifestação clínica da SRE.

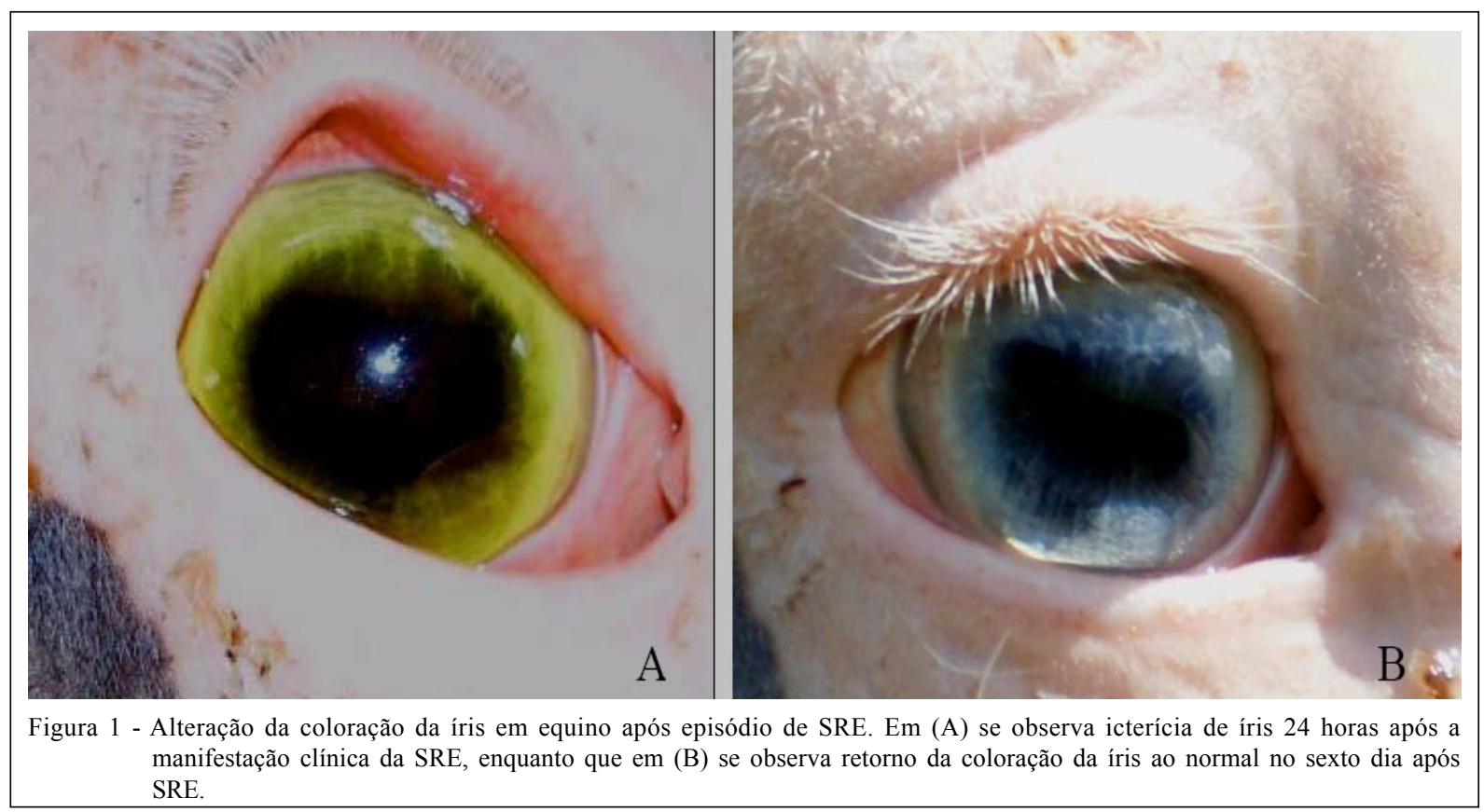

Ciência Rural, v.39, n.7, out, 2009. 
A relação cátion-anion dietética parece ser a explicação mais plausível para a associação entre dieta rica em concentrado e SER, nesse caso, além do longo período de inatividade física. Dieta rica em concentrado tende a apresentar relação cátion-ânion baixa e, além disso, é acidogênica devido ao relativo déficit de cátions em relação a ânions.

Equinos com SRE podem apresentar, tanto acidose metabólica (THOMASSIAN, 2005), quanto alcalose metabólica hipoclorêmica (HARRIS \& MAYHEW, 2000), apesar de a última ser mais comum. No caso de exercícios prolongados, como, por exemplo, cavalgadas, devido à necessidade de termorregulação, ocorre sudorese significativa, com grande perda de íons cloreto, conforme observado neste relato (Tabela 1), e reabsorção renal compensatória de bicarbonato para manutenção da eletronegatividade dos fluidos corpóreos (LINDINGER \& WALLER, 2008). Dessa forma, a administração de fluidoterapia com fluidos acidificantes e ricos em íons cloreto, a exemplo da solução salina fisiológica $0,9 \%$, é benéfica nos casos de SRE. Por outro lado, a utilização de pequenas quantidades da solução de ringer lactato pode ser benéfica em alguns casos de SRE, pois o lactato presente nessa solução pode ser convertido em glicose/ glicogênio por meio do ciclo de Cori, atuando como aporte energético.

No segundo dia, a interpretação da hematologia revelou neutrofília $\left(16.192\right.$ céls $\left.\mu 1^{-1}\right)$ e linfopenia (736céls $\mu \mathrm{l}^{-1}$ ) resultantes, provavelmente, do excesso de glicocorticóides na circulação. O mecanismo da neutrofilia envolveu o desvio de neutrófilos do pool marginal para o circulante, a diminuição da migração de neutrófilos do sangue para os tecidos e a mobilização aumentada de neutrófilos a partir da medula óssea. Já a linfopenia resultou da diminuição da recirculação ou redistribuição dos linfócitos dentro dos tecidos linfóides. Hiponatremia, hipocloremia, hipocalcemia e hipercalemia foram identificadas nesse caso e são comuns após condições extremas de exercício e sudorese excessiva (SANTOS et al., 2001).

A concentração sérica de CK elevou-se 25 vezes acima do valor de referência, demonstrando lesão muscular intensa. No entanto, o uso isolado da atividade sérica das enzimas musculares para diagnóstico da SRE é controverso. Problemas surgem quando são encontradas atividades enzimáticas elevadas sem sintomatologia clínica ou sinais clínicos sem elevação da concentração sérica das enzimas musculares. A presença de sinais clínicos sem elevação da atividade enzimática representa falso diagnóstico (HARRIS \& MAYHEW, 2000). No caso descrito neste trabalho, a elevação das atividades séricas de CK, AST e LDH foram acompanhadas por sinais clínicos de SRE, confirmando o diagnóstico.

A hiperbilirrubinemia observada na bioquímica sérica manifestou-se clinicamente por icterícia das membranas mucosas e da íris. O acúmulo de bilirrubina ou seus conjugados nos tecidos produz icterícia, caracterizada por elevadas concentrações séricas de bilirrubina e deposição de pigmentos de bilirrubina na pele, na esclera e nas membranas mucosas, conferindo uma coloração amarelada a esses tecidos. A deposição de pigmentos de bilirrubina, em estruturas oculares, tem sido descrita somente nos tecidos da conjuntiva e esclera. Não existem relatos descrevendo a deposição de pigmentos de bilirrubina na íris, na literatura veterinária. No entanto, PHINNEY et al. (1989) descreveram quatro casos de icterícia corneal em seres humanos. Provavelmente, a proximidade da íris aos vasos sanguíneos do limbo e da coróide pode tornar a íris predisposta à deposição de pigmentos de bilirrubina. É possível que a deposição de pigmentos de bilirrubina na íris ocorra em equinos hiperbilirrubinêmicos. No entanto, como a coloração da íris da maior parte dos equinos é escura, tal alteração não é identificada clinicamente. Neste relato, a íris heterocromática possibilitou a identificação da icterícia.

A compactação cecal ocorreu secundária à hiperatividade simpática resultante da dor muscular, além da hipocloremia e hipocalcemia. A hiperatividade simpática provoca redução da motilidade propulsiva e aumento do tônus dos esfíncteres, resultando em acúmulo de ingesta no trato gastrintestinal e consequente formação de compactação. A hipocloremia secundária à perda de íons cloreto pela sudorese indiretamente contribuiu para a alteração da motilidade e formação da compactação. Cloreto é necessário para a liberação de cálcio a partir do reticulo sarcoplasmático e, dessa forma, sua diminuição na circulação predispõe o eqüino para a diminuição da motilidade intestinal propulsiva (MELO et al., 2007).

A ocorrência de icterícia da íris neste relato serve de alerta para a ocorrência dessa alteração em equinos hiperbilirrubinêmicos, principalmente aqueles com íris heterocromática.

\section{AGRADECIMENTOS}

O primeiro autor agradece a bolsa do Conselho Nacional de Desenvolvimento Científico e Tecnológico (CNPq).

\section{FONTES DE AQUISIÇÃO}

a-Equipalazone, Marcolab, Duque de Caxias, RJ, Brasil. b-Muscoril, Nature's Plus Farmacêutica, Hortolândia, SP, Brasil.

Ciência Rural, v.39, n.7, out, 2009. 


\section{REFERÊNCIAS}

ALEMAN, A. A review of equine muscle disorder. Neuromuscular Disorders, v.18, p.277-287, 2008.

BAXTER, G.M.; TURNER, A.S. Doenças ósseas e estruturas relacionadas. In: STASHAK, T.S. Claudicação em equinos segundo Adams. 5.ed. São Paulo: Roca, 2006. p.401-415.

FELDMAN, B. et al. Schalm's veterinary hematology. 5.ed. Philadelphia: Lippincott Williams \& Wilkins, 2000. $1344 \mathrm{p}$.

GOMIDE, L.M.W et al. Concentrações sanguíneas de lactato em equinos durante a prova de fundo do concurso completo de equitação. Ciência Rural, v.36, p.509-513, 2006. Disponível em: <http:/ /www.scielo.br/scielo.php?script=sci_arttext\&pid $=$ S0103$84782006000200022 \& \operatorname{lng}=$ pt\&nrm $=$ iso $>$. Acesso em: 15 jun. 2008. doi: $10.1590 / \mathrm{S} 0103-84782006000200022$.

HARRIS, P.A.; MAYHEW, I.G. Enfermidade musculoesquelética. In: REED, S.M.; BAYLY, W.M. Medicina interna equina. Rio de Janeiro: Guanabara Koogan, 2000. p.320-367.

LINDINGER M. I.; WALLER A. Muscle and blood acid-base physiology during exercise and response to training. In HINCHCLIFF, K.W.et al. Equine exercise physiology The science of exercise in the athletic horse. London: Saunders, 2008. p.350-381.

MACLEAY, J.M. et al. Effect of ration and exercise on plasma creatina kinase activity and lactate concentration in Thoroughbred horses with recurrent exertional rhabdomyolysis. American Journal Veterinary Research, v.61, p.1390$1395,2000$.

MARTINS, C.B. et al. Determinação de variáveis bioquímicas em equinos antes e após a participação em prova de enduro.
Revista Brasileira de Ciência Veterinária, v.12, p.62-65, 2005.

MELO, U.P. et al. Íleo adinâmico em equinos: fisiopatologia e tratamento. Arquivo de Ciência Veterinária e Zoologia da UNIPAR, v.10, p.49-58, 2007. Disponível em: <http:// revistas.unipar.br/veterinaria/article/viewFile/572/500>. Acesso em: 25 jun. 2008

PHINNEY, R.B. et al. Corneal icterus resulting from stromal bilirubin deposition. Ophthalmology, v.96, p.1212-1214, 1989.

SANTOS A.S. et al. Serum electrolyte and total protein alterations in Pantaneiro horse during long distance exercise. Arquivo Brasileiro de Medicina Veterinária e Zootecnia, v.53, p.351-357, 2001. Disponível em: <http://www.scielo.br/ scielo.php? script=sci arttext\&pid=S 0102 $09352001000300013 \& \operatorname{lng}=\mathrm{pt} \& n r m=i s o>$. Acesso em: 14 jun. 2008. doi: 10.1590/S0102-09352001000300013.

VALENTINE, B.A. et al. Dietary control of exertional rhabdomyolysis in horses. Journal American Veterinary Medical Association, v.212, p.1588-1593, 1998.

TEIXEIRA-NETO, A.R. et al. Alterations in muscular enzymes of horses competing long-distance endurance rides under tropical climate. Arquivo Brasileiro de Medicina Veterinária e Zootecnia, v.60, p.543-549, 2008. Disponível em: <http:// www.scielo.br/scielo.php?script $=$ sci arttext\&pid $=\mathrm{S} 0102$ $09352008000300004 \& \operatorname{lng}=\mathrm{pt \& nrm}=\mathrm{iso}>$. Acesso em: $25 \mathrm{dez}$. 2008. doi: 10.1590/S0102-09352008000300004.

WATANABE, M.J. et al. Alterações do $\mathrm{pH}$, da $\mathrm{P}$ e da $\mathrm{P}$ arteriais e da concentração de lactato sangüíneo de ${ }^{02}$ cavalos ${ }^{\mathrm{C} Q 2}$ raça Árabe durante exercício em esteira de alta velocidade. Arquivo Brasileiro de Medicina Veterinária e Zootecnia, v.58, p.320-326, 2006. Disponível em: <http://www.scielo.br/ scielo.php? script=sci_arttext\&pid=S 0102 $9352006000300006 \& \operatorname{lng}=$ pt\&nrm=iso $>$. Acesso em: 12 jun. 2008. doi: $10.1590 / \mathrm{S} 0102-09352006000300006$. 